Journal of Sustainable Development of Transport and Logistics

journal home page: https://jsdtl.sciview.net

Edirisinghe, L. (2018). The virtual container yard: A complimentary tool to optimize

collaboration in shipping. Journal of Sustainable Development of Transport and Logistics,

3(2), 74-81. doi:10.14254/jsdtl.2018.3-2.5.

\title{
The virtual container yard: A complimentary tool to optimize collaboration in shipping
}

\section{Lalith Edirisinghe}

Colombo International Nautical and Engineering College (CINEC Campus),

Millennium Drive, IT Park, Malabe, Sri Lanka

Faculty of Management, Humanities and Social Sciences, Department of Logistics and Transport

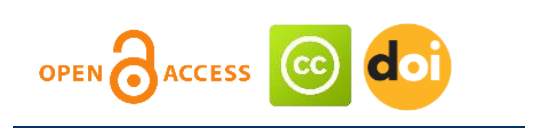

\section{Article history:}

Received: July 26, 2018

1st Revision: August 16,

2018

Accepted: October 25, 2018

DOI:

10.14254/jsdtl.2018.3-2.5
Abstract: Unlike in other ship types, the container ships cannot offer their services without containers and the shipping space become ineffective. Therefore, containers and slots are complimentary and indispensable service component in liner container shipping. The virtual container yard (VCY) is a modern concept and an effective CIM solution that underpins the collaboration between carriers. Carriers already have common platforms to interchange slots thus it is just one fine step away from implementing the similar strategy for containers. It is, through these findings, expected to change the carriers' myopic view about the container interchange. The actual container statistics in Sri Lanka was extracted from the industry as the source of input for the study. The paper reveals that the VCY could reduce the inventory management cost by 19 percent. Carriers opted to interchange the container slots in cellular ships more than three decades ago. This paved the way for strong collaboration between carriers and provided many financial advantages. It helped in securing economic advantages through scale of economies in highly completive shipping industry. This paper provides empirical evidences of the financial savings of container interchange under different container sizes and types.

Keywords: slots, shipping, virtual container yard, carriers, inventory. 


\section{Introduction}

Shipping is a derived demand in economic terms (Edirisinghe, Zhihong, \& Wijeratne, 2015). Accordingly, the shipping industry has been playing a vital role in sustaining world trade and the economy. Annually, millions of tons of consumer items are shipped from various points of origin to thousands of ports around the world. UNCTAD forecasts world seaborne trade to increase by 2.8 per cent in 2017, with total volumes reaching 10.6 billion tons (UNCTAD, 2017). However, shipping industry has faced challenging conditions over the past five years. The container shipping industry has been running up losses that enhanced collaboration between shipping companies reaching a critical momentum to secure a course to sustainable profits. The world's major container shipping lines made estimated collective operating losses of $\$ 3.5$ billion in 2016 (Will , 2017). This industry is continuing to experience with mergers and acquisitions particularly within the container shipping industry. In a way, this trend could be considered as a means of survival in response to the adversities their sector suffered. While there are many reasons for this status of shipping, ineffective container inventory management is one of the key factors that created economic loss and marketing disadvantages to the shipping industry (Edirisinghe, Zhihong, \& Wijeratne, 2016 a). Container inventory imbalance carry a 22 percent of total container cost (Alderton, 2004). The slot interchange between alliance partners is successfully operative but collaboration between carriers with respect to containers which is still not popular and effective. The basic and traditionally established solution to address the Container Imbalance problem has been the "re-positioning" those empty containers from locations where they are excess to that of deficit. The shipping industry perceives this as the best (effective and efficient) and troublefree solution due to various reasons. The researcher found no evidences of previous researches with respect to container exchange strategies were found thus the benefits of container exchange have rarely been evaluated. The shortages of containers result a cost of empty reposition (Inward) while the excess lead to a cost of empty reposition (outward). Therefore, minimizing the quantity of repositioning (both inward and outward) is the primary objective of the carriers thus reduces the operating cost of container carriers. In the collaborative nature the shortage of certain carriers can be set off with excess units of others. As a result, on one hand, the need for outward movements (of those who are excess) of empty units is reduced. On the other hand, the needs for inward movements (of those who are in deficit) are minimized. In other words, exchange of one container will curtail two movements of empty containers.

The proposed VCY is a tool that leads to common CIM system across the industry. Most of the carriers already have provisions to interchange containers (Edirisinghe, Zhihong, \& Wijeratne, Container Interchange: the $6 \mathrm{R}$ Model Approach, 2018). The main purpose of the paper is to evaluate the feasibility of implementing the VCY in Sri Lanka based on historical data as a case study. As cited in (Brito \& Konings, n.d.), containers remain for about half the time of their lifetime being idle and worldwide about $20 \%$ of total container flows at sea are empty (Mittal, 2008) and the costs of repositioning are about USD 400 per container or USD 395 (Yen, 1994). Almost 1 out of 4 containers $(25 \%)$ is carrying just plain air today without any profit to the vessel (Akca, 2013). Only $20 \%$ of a container's time is spent at sea, while $56 \%$ is unproductive (Boile, Theofanis, \& Mittal, 2004). Despite the unbelievable financial benefits of containerization, the estimated empty container repositioning costs accounted for USD 20 billion on the global level in 2002 (Karmelic, Dundovic, \& Kolanovic, 2012). It was not possible to find a reliable update regarding the empty reposition cost as ate year 2018 on the global scale. However, it was recorded that empty container volumes remain stable ranging from $18 \%$ to $22 \%$ between 1990 and 2011. Despite such alarming trend the industry focusses on finding innovative methods to solve the problem seems very moderate. For example, empty container movement has been as high as $38.28 \%$ as against the laden container movements according to container statistics in Sri Lanka (SLPA, 2012); (SLPA, 2015); (SLPA, 2013) CASA Per. Review, 2004-2014) but there is no deliberate attempt to reduce this cost.. The average cost of reposition as calculated by the researcher is approximately USD 350 per container.

The fundamental prerequisite in container sharing is that there should be certain carriers with excess inventories while others suffer from deficit of containers at the same location and at the same time. This leads to a further limitation considering the types and sizes of container inventories. For example, there should be at least one carrier with a shortage of $20^{\prime} \mathrm{GP}$ containers with another has excess the same type and size ${ }^{1}$ (i.e. $20^{\prime} \mathrm{GP}$ ). The key disruption in attracting carriers to implement the VCY concept is the hypothetical belief of non-existence of above fundamental prerequisite. Therefore, it is necessary to prove through real data that there is a potential of

${ }^{1}$ Containers have different types such as GP or ST (General Purpose or Standard), High cube (HC), Reefer (RF), Open Top(OT), Flat rack(FR), and different sizes $\left(20^{\prime}, 40^{\prime}, 45^{\prime}\right)$ in order to carry various commodities more effectively and efficiently 
implementing the VCY. Accordingly. this paper provides empirical evidences based on real container data pertaining port of Colombo, Sri Lanka.

\section{Research methods}

This is a combination of desk research based on the import and export container statistics pertaining to Sri Lanka and interviews with shipping line personnel and other industry experts. The existing practice reflects the "Work alone" scenario as lines presently do not share containers among carriers. The proposed scenario under collaboration may facilitate sharing of containers that ultimately leads to a "Common container yard".

The actual container statistics of year 2013 was extracted from the industry as the source of input for the study. The data of 2013 was used as the size/type wise container data are not published in Sri Lanka. Therefore, this research was conducted using 2013 container on the assumption that total container throughput has no significant impact in the analysis and research outcome. The annual container data for last five years is provided in table 1 and it reveals an increase in the share of imports (in terms of TEUs) from 65 percent to 71 percent. It shows that the gap between imports and export volumes have been widened. It is evident that the impact of container inventory ambiance too has proportionately increased.

\section{Step 1:}

The monthly container statistics have been calculated based on two scenarios as follows.

Scenario 01 (Work alone)

When carriers do not share containers, the total shortage/excess quantity can be calculated as per following steps

(i) Calculate the individual inventories (both deficit and excess) during each month by each carrier

(ii) Obtain the sum of above (i) for January to December that reflect the annual shortage/excess quantity Scenario 02 (Collaboration)

The total shortage/excess quantity, if carriers share containers, is calculated as per following steps

(i) Calculate the overall inventories (both deficit and excess) by all carriers during each month

(ii) Obtain the sum of above (i) for January to December that reflect the annual shortage/excess quantity

\section{Step 2}

To compare the excess and shortage of containers that is estimated to be generated through these two scenarios, the data are tabulated in the table 1 and 2 respectively. It illustrates the existing "work alone and proposed "collaboration" using real trade statistics pertaining to 40'GP containers in 2013 in Sri Lanka.

\section{Step 3}

There were different opinions in literature regarding the cost of empty container reposition cost. It ranges from USD 350 to 500 for a TEU. Therefore, to obtain more accurate cost following cost calculation was done in the real file scenario considering the port tariff as at 2014. However, two key assumptions were made based on the views of industry experts regarding current trade practices.

(i) Empty reposition into Sri Lanka are originated in India (Port Nhava Shiva)

(ii) Empty containers evacuated from Sri Lanka are destined in Singapore.

\section{Research results}

The interviews revealed that some strong evidences are required to challenge the mind set of carriers. It was noted that some industry experts have a negative perception about its implementation of the VCY although they generally accept the concept as a solution to CIM problems. In other words, the common consensus of carriers about the container interchange is over casted with following hypothetical presumptions.

(i) Container imbalance has a positive correlation with trade imbalance. Therefore, greater trade imbalance in a port pair will result equally greater container imbalance for all CSL who serve the respective trade lane. Accordingly, the container inventory of all carriers at a given time and at a given location are identical to each other thus there is no room for exchange.

(ii) Seasonal variations have equal impact on all carriers serving a trade lane at a specific period thus logically there is no possibility to exchange. (For example, if all CSL have excess inventories during month of December in Sri Lanka no exchange is possible) 
(iii) Every port has high demand for specific types and/or sizes for exports while it receives majority of imports in different types/sizes. This phenomenon is equally applicable to all carriers serving that port leaving no room for exchange. (For example, any carrier will have excess 20's and a deficit of 40s in Sri Lanka consistently given the trade norms)

Table 1: The trend of import and export volumes in Sri Lanka in TEUs

\begin{tabular}{lllll} 
Year & Imports & As a $\%$ & Exports & As a $\%$ \\
\hline 2013 & 476982 & 65 & 256396 & 35 \\
2014 & 518951 & 66 & 269931 & 34 \\
2015 & 573518 & 69 & 263363 & 31 \\
2016 & 631032 & 70 & 270561 & 30 \\
2017 & 668226 & 71 & 277563 & 29 \\
\hline
\end{tabular}

There are two fundamental mechanisms to manage the container inventories namely, (i) carriers work alone (as it happens at present, or (ii) carriers work collaboratively (according to proposed container interchange model). Table 2 and Table 3 provide estimated data of few major carriers operated in port of Colombo in 2013.

\begin{tabular}{|c|c|c|c|c|c|c|c|c|c|c|c|c|c|c|}
\hline & MKL & APL & EMC & NYK & $\mathrm{OOCL}$ & MOSK & MSC & PIL & SAF & $\mathrm{SCl}$ & WAN & YML & $\overline{Z I M}$ & Final outcome \\
\hline JAN & 81 & 107 & 36 & 54 & 23 & 8 & 73 & 28 & 14 & 36 & 27 & 8 & $\frac{2110}{2}$ & 903 \\
\hline \begin{tabular}{|l|} 
FEB \\
\end{tabular} & 51 & 83 & 23 & 26 & 45 & 48 & 129 & 20 & 9 & 25 & $\mid 2$ & 8 & 19 & 655 \\
\hline \begin{tabular}{|l} 
MAR \\
\end{tabular} & \begin{tabular}{|l|}
177 \\
\end{tabular} & 51 & 196 & $\mid 127$ & 6 & 118 & 134 & 60 & 37 & 23 & 2 & 18 & 3 & 1,149 \\
\hline APR & 38 & 62 & 98 & 30 & 8 & 48 & 64 & 11 & 29 & 12 & 5 & 15 & 2 & 885 \\
\hline \begin{tabular}{|l|} 
MAY \\
\end{tabular} & \begin{tabular}{|l|}
117 \\
\end{tabular} & 29 & 66 & 22 & 48 & 46 & 133 & 3 & 76 & 23 & 13 & 18 & 2 & 923 \\
\hline JUN & 29 & 36 & 25 & 20 & 58 & 26 & 30 & 16 & 26 & 14 & 43 & 17 & 9 & 562 \\
\hline JUL & \begin{tabular}{|l|}
154 \\
\end{tabular} & \begin{tabular}{|l|}
42 \\
\end{tabular} & 101 & \begin{tabular}{|l|}
17 \\
\end{tabular} & 7 & 43 & 101 & 31 & 4 & 3 & 15 & 26 & 13 & 834 \\
\hline \begin{tabular}{|l} 
AUG \\
\end{tabular} & 409 & 135 & 101 & 28 & 25 & 19 & 171 & 20 & 66 & 9 & 19 & 4 & 12 & 1,188 \\
\hline SEP & 166 & 61 & 35 & 50 & 32 & 62 & 160 & 9 & 90 & 6 & 12 & 0 & 7 & 899 \\
\hline OCT & \begin{tabular}{|l|}
13 \\
\end{tabular} & 96 & 55 & 28 & 6 & 83 & 146 & 15 & 81 & 19 & 22 & 25 & 13 & 793 \\
\hline NOV & \begin{tabular}{|l|}
193 \\
\end{tabular} & 99 & 59 & 28 & 23 & 4 & 72 & 2 & 43 & 20 & 23 & 42 & 24 & 833 \\
\hline DEC & 131 & 6 & 99 & 104 & 41 & 5 & 148 & 35 & 28 & 1 & \begin{tabular}{|l|}
47 \\
\end{tabular} & 3 & 22 & 862 \\
\hline Total & 1559 & 807 & 894 & 534 & 322 & 510 & 1361 & 250 & 503 & 191 & 230 & 184 & 128 & 10,486 \\
\hline
\end{tabular}

The final outcome stated in Table 2 is 10,486 which means there had been more than 40' GP containers reposition to balance the container inventory imparlance by the respective carriers. On the contrary Table 3 states the final outcome (if the carriers opted to interchange containers between them) as 794 container movements only.

\section{Table 3: Total empty container repositions in the proposed "collaboration" scenario}

\begin{tabular}{|l|l|l|l|l}
\hline & MKL & APL & EMC & NYK \\
\hline JAN & -81 & 107 & -36 & -54 \\
\hline FEB & -51 & 83 & -23 & -26 \\
\hline MAR & -177 & 51 & -196 & 127 \\
\hline APR & -38 & -62 & 98 & 30 \\
\hline MAY & 117 & 29 & -66 & 22 \\
\hline JUN & 29 & -36 & 25 & 20 \\
\hline JUL & 154 & 42 & 101 & 17 \\
\hline AUG & 409 & -135 & 101 & -28 \\
\hline SEP & 166 & -61 & -35 & 50 \\
\hline OCT & -13 & -96 & -55 & -28 \\
\hline NOV & -193 & -99 & 59 & -28 \\
\hline DEC & -131 & -6 & 99 & 104 \\
\hline Total & 191 & -183 & 72 & 206 \\
\hline
\end{tabular}

\begin{tabular}{|l|l|l|l|l|l|l}
\hline OOCL & MOSK & MSC & PIL & SAF & SCI & WAN \\
\hline 23 & 8 & -73 & 28 & -14 & -36 & 27 \\
\hline 45 & -48 & -129 & 20 & 9 & -25 & -2 \\
\hline 6 & 118 & -134 & 60 & -37 & -23 & -2 \\
\hline 8 & -48 & -64 & 11 & 29 & -12 & -5 \\
\hline 48 & -46 & -133 & -3 & 76 & -23 & 13 \\
\hline 58 & -26 & -30 & 16 & 26 & 14 & 43 \\
\hline-7 & 43 & -101 & 31 & -4 & -3 & 15 \\
\hline 25 & -19 & -171 & -20 & 66 & -9 & 19 \\
\hline 32 & -62 & -160 & -9 & 90 & -6 & 12 \\
\hline-6 & -83 & -146 & -15 & 81 & -19 & -22 \\
\hline 23 & 4 & -72 & -2 & 43 & 20 & 23 \\
\hline 41 & -5 & -148 & 35 & -28 & -1 & 47 \\
\hline 296 & -164 & -1361 & 152 & 337 & -123 & 168 \\
\hline
\end{tabular}
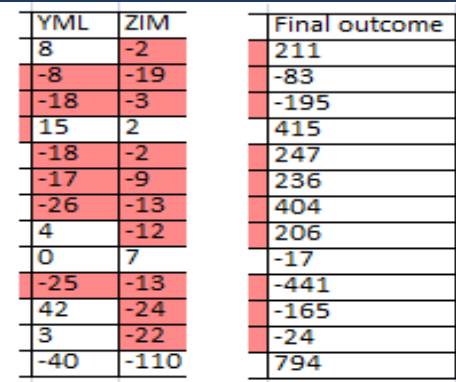

Key: shaded boxes with (-) in front of the number indicate deficit inventory while clear boxes denote excess inventories

Therefore, the difference between these two outcomes (i.e. 9692 container movements) reveals the saving that could generate through collaboration. In order to rightly calculate the financial benefits of the proposed concept the cost of container reposition should be defined.

This computation in table 4 gives more accurate information as it provides cost for 20' containers and 40' separately. Usually terminal operators do the invoicing based on size/type tariff and not based on TEU. For simplicity average cost per 20' [(USD 396.60+298.60) $/ 2=347.60]$ and $40^{\prime}[(632.00+504.20) / 2=568.10]$ were taken. 


\begin{tabular}{|c|c|c|c|c|c|}
\hline \multicolumn{3}{|c|}{ Exporting empty containers to Singapore from Colombo } & \multicolumn{3}{|c|}{ Importing empty containers to Colombo from Nhava Shiva } \\
\hline Description of Cost & 20' Empty & 40’Empty & Description of Cost & 20'Empty & 40’Empty \\
\hline Lift on Charge at CFS & USD 7.00 & USD 14.00 & Lift on Charge at CFS & USD 2.00 & USD 4.00 \\
\hline Transport CFS to Port & USD 25.00 & USD 35.00 & Transport CFS to Port & USD 20.00 & USD 40.00 \\
\hline $\begin{array}{l}\text { Colombo PHC for loading } \\
\text { (Port Handling Charge) }\end{array}$ & USD 118.60 & USD 179.20 & $\begin{array}{c}\text { Nava Shiva PHC for } \\
\text { loading (Port Handling } \\
\text { Charge) }\end{array}$ & USD 57.00 & USD 87.00 \\
\hline $\begin{array}{l}\text { Slot cost (Colombo to } \\
\text { Singapore) }\end{array}$ & USD 40.00 & USD 80.00 & $\begin{array}{c}\text { Slot cost (Nava Shiva to } \\
\text { Singapore) }\end{array}$ & USD 75.00 & USD 150.00 \\
\hline $\begin{array}{l}\text { Singapore Discharge } \\
\text { PHC }\end{array}$ & USD 180.00 & USD 275.00 & Colombo Discharge PHC & USD 118.60 & USD 179.20 \\
\hline $\begin{array}{l}\text { Transport from port to } \\
\text { CFS }\end{array}$ & USD 25.00 & USD 35.00 & $\begin{array}{l}\text { Transport from port to } \\
\text { CFS }\end{array}$ & USD 19.00 & USD 30.00 \\
\hline Lift off Charge at CFS & USD 7.00 & USD 14.00 & Lift off Charge at CFS & USD 7.00 & USD 14.00 \\
\hline Total & USD 402.60 & USD 632.00 & Total & USD 298.60 & USD 504.20 \\
\hline
\end{tabular}

Source: (Edirisinghe, Zhihong, \& Wijeratne, 2015)

It is plainly visible in the table 5 that the estimated saving exceeds USD 17.5 Million reflecting a substantial saving of $19 \%$ against the current empty reposition cost. Table 5 finally provides the estimated savings expected from each container type namely, 20'GP, 40'GP and $\mathrm{HC}$, 45' $\mathrm{HC}$ and 20'\& 40' RF.

\begin{tabular}{|c|c|c|c|c|c|}
\hline $\begin{array}{c}\text { Container Type\& } \\
\text { Size } \\
\end{array}$ & $\begin{array}{c}\text { Imbalance when } \\
\text { Work alone }\end{array}$ & $\begin{array}{c}\text { Imbalance when } \\
\text { Collaborate }\end{array}$ & $\begin{array}{l}\text { Reduction of empty } \\
\text { reposition }\end{array}$ & $\begin{array}{l}\text { Savings from } \\
\text { VCY USD }\end{array}$ & $\begin{array}{l}\text { Saving as \% of } \\
\text { reposition cost }\end{array}$ \\
\hline 20 'GP & 158221 & 156285 & 1936 & $672,953.60$ & 1.22 \\
\hline 40 'GP & 10486 & 794 & 9692 & $5,506,025.20$ & 92.43 \\
\hline $40 ' \mathrm{HC}$ & 44586 & 27842 & 16744 & $9,512,266.40$ & 37.55 \\
\hline $45^{\prime} \mathrm{HC}$ & 2155 & 101 & 2054 & $1,166,877.40$ & 95.31 \\
\hline $20^{\prime} \& 40^{\prime} R F$ & 5975 & 4791 & 1184 & $672,630.40$ & 19.82 \\
\hline Total (without & & & & & \\
\hline OT/FR/FB) & 221423 & 189813 & 31610 & $17,530,753.00$ & 19.29 \\
\hline
\end{tabular}

Also, the container size wise analysis shows that the saving from 2 categories namely, 40' GP and 45" HC exceeds $90 \%$ proving the myopic view of the shipping industry is baseless. Of course, exchanging $20^{\prime}$ GP containers is not feasible in Sri Lanka. However, it may be feasible to another country with different trade patterns and commodity movements. Sri Lanka has exported 256,396 TEUs during the year 2013. If the estimated saving of USD $17,530,753.00$ is allocated to reduce the export freight rate (to promote the country's export industry), the export freight rates from Sri Lanka could be reduced by USD 68.37 per TEU. Apart from the direct financial benefits a substantial impact on the environmental pollution could have been gained with the expected reduction of empty container movements globally. Given the serious financial problems that continue in shipping cost cutting measures would be the key in sustainability.

\section{Discussion and results}

The collaboration of shipping companies in the perspective of slots will stay and grow. Consolidation, whether through alliances or mergers and acquisitions (M\&A), will continue in the container shipping industry into 2018 as companies try to boost market share, improve efficiency and handle intensifying competition and persistent oversupply (Mishra, 2017). Therefore, the opportunity to interchange containers between them also will grow if the carriers focus on this strategic solution. However, shipping lines have conveniently neglected the option of interchanging containers within these consortiums. This paper provides an insight about this paradox in container liner shipping, while providing scientifically proved factor analysis that identifies the weights of respective components. The VCY may contain containers belong to many carriers with multiple objectives, interests, costing, ROI, procedures, practices, and even different cultures, languages, time zones, values and attitudes. It makes the mechanism that the VCY should operate more complicated and it may need very professional approach. However, it is a known fact that most practitioners in shipping industry usually reluctant to follow recommendations of scientific researches. Since the container imbalance problem is making substantial burden on carriers and their 
customers it is a duty and responsibility of the scholars to link the academia and practitioners address these types of ever widening industry gaps and myopic view.

Previous researches reveal that the industry participants consider container inventory imbalance as a serious issue but only half of them have a standard container inventory management policy. This gives a clear indication that container shipping lines needs to develop a proper system to bridge the industry gap (Edirisinghe, Zhihong, \& Wijeratne, 2016 a). Carriers usually focus on the service Agreements (Derive accuracy of forecast through Service agreements with customers); and Freight Drop Exports (Reduce export freight in response to foreseeable excess at a specific origin) would be influenced the highest number of factors as the common container management strategies (Edirisinghe, Jin, \& Wijeratne, 2017). The VCY concept visualizes and approach more longterm advantage of the carriers rather than its short-term marketing complications. With the improving technology and statistical capabilities finding a solution for the highly complicated problem is possible. What is needed is that the commitment and broader vision of the stakeholders. Even the slot exchange between carriers did not attract the shipping industry in its initial stages. But now it pays evident to the industry as a whole. In addition to vessel sharing these alliances gradually extended the collaboration to other areas such as, service rationalization, operating expense sharing, equipment interchange, and joint service contracts (Edirisinghe, 2017). It is recommended that this will be very easy to tackle by the consortium partners that are already sharing the slots, calling same ports of call, satisfactorily coordinating operational and commercial matters amicably. It was established that five key components namely, operational, legal, branding, benefits, and feasibility may influence carriers' decision with respect to container interchange (Edirisinghe, Zhihong, \& Wijeratne, 2016 b). Therefore, the first step in the right direction could be the selective ports and selected carriers who wish to take a lead in this. Particularly the shipping agents perceived it as a serious marketing threat. The VCY cares the sustainability of carriers. It considers the environmental impacts and green logistics. The annual emissions from the world's merchant fleet have already reached $1.12 \mathrm{bn}$ tonnes of $\mathrm{CO} 2$, or nearly $4.5 \%$ of all global emissions of the main greenhouse gas set to rise by a further $30 \%$ by 2020 (Vidal, 2008). It aims reduce the need for proportionate expansions in global container inventories through the synergy in many carriers sharing the least inventories. It is optimistic that reasonable freight reductions may realize as a result of reduced empty container reposition cost to carriers. These costs are invariably paid by the consumers as the cost of freight in the consumer goods. Therefore, carriers should be able reflect these savings in the freight rates. These are quite a few advantages that VCY may provide. The container imbalance in Sri Lanka could have been reduced by 31,610 containers in 2014 if carriers opted to exchange containers. The estimated saving is approximately USD 12.6 Million (Edirisinghe \& Zhihong, The Benefits of Container Exchange between Carriers: A Case Study, 2016 a).

In a services marketing environment that carriers used to compete with other carriers, multiple carriers offering space in the same ship was naturally viewed as selling a 'commodity' instead of a product. The brand images, brand values, and various other completive edges each carrier maintained were challenged in a consortium. Even this created a big havoc in the pricing policies of some carriers. However, gradually carriers realized that the benefits that the slot sharing gives to each carrier as well as the whole world are enormous. Today, it offers the scale of economies advantage and carriers can expand vessel sizes irrespective of their individual capabilities. Accordingly, the researcher is positive that the industry will gradually take advantage of the VCY.

Absence of collaboration in liner shipping in the form of container sharing is a serious issue that add a substantial cost to shipping lines. The shipping lines successfully collaborate and share slots for more than two decades and the alliances are increasing its sharing activities. Therefore, the absence of collaboration with respect to containers is quite a paradox. While the slot exchange provides the scale of economies benefits to the carriers, the container exchange may give them the synergy effect to increase their profits. This concept has become extremely important with the cost that adds to transportation due to container inventory imbalance.

\section{Conclusions}

VCY could reduce the container imbalance by $19.3 \%$ approximately. It also computes a reduction of USD 68.40 from each export container after implementation of the VCY. This paper will lead to a paradigm shift in container shipping as it provides awareness about the feasibility of implementing VCY in the consortiums and change the carriers' myopic view regarding container interchange. Although, the cost of empty container reposition is primarily borne by the respective shipping lines later it is recovered from the exporters as a higher freight rate and ultimately paid by the consumer of the cargo. Therefore, this helps reduce the consumer goods that are being 
imported to the country. However, the carriers are compelled to share the information about their individual container inventories. The major limitation is that most of information that may be required for the study is usually considered by the industry as confidential.

\section{Appendix A. Supplementary material}

Supplementary data associated with this article can be found, in the online version, at https://jsdtl.sciview.net

\section{Funding}

The authors received no direct funding for this research.

\section{Citation information}

Edirisinghe, L. (2018). The virtual container yard: A complimentary tool to optimize collaboration in shipping. Journal of Sustainable Development of Transport and Logistics, 3(2), 74-81. doi:10.14254/jsdtl.2018.3-2.5.

\section{References}

Akca, N. (2013, 11 18). Collapsible Containers. Retrieved 08 01, 2014, from http://morethanshipping.com/collapsible-containers/

Alderton, P. M. (2004). Reeds Sea Transport Operation and Economics (Fifth ed.). London: Adlard Coles Nautical.

Boile, M., Theofanis, S., \& Mittal, N. (2004). Empty Intermodal Containers - A Global Issue. Evanston Illinois: Transportation Research Forum, 45th Annual Forum.

Brito, M. P., \& Konings, R. (n.d.). Container management strategies to deal with the East-West flows imbalance. Retrieved April 26, 2013, from http://www.fucam.ac.be/S\%C3\%A9minaires,\%20conf\%C3\%A9rences\%20et\%20colloques/Nectar/images /debrito_konings.pdf

Chiang, J. (2013). Outlook of global container port market with a focus on Asia. 11th ASEAN Port and Shipping 2013-Philippines: Drewry Maritime Advisors.

Edirisinghe, L. (2017). Smart Container Inventory Management: A Conceptual Approach. CINEC Academic Journal, 2(1), 105-110.

Edirisinghe, L., \& Zhihong, J. (2016 a). The Benefits of Container Exchange between Carriers: A Case Study. Moratuwa: Sri Lanka Society for Transport and Logistics.

Edirisinghe, L., Jin, Z., \& Wijeratne, A. (2017). Factors that Influence Container Inventory Management Strategies. International Conference on Management and Economics (pp. 509-526). Ruhuna: University of Ruhuna.

Edirisinghe, L., Zhihong, J., \& Wijeratne, A. (2015). Evaluation of Expected Payoff through Container interchange between shipping lines: a solution to container inventory imbalance in Sri Lanka. Int. J. Logistics Systems and Management, 21(4), 503-533.

Edirisinghe, L., Zhihong, J., \& Wijeratne, A. (2016 a). The Global Impact of Container Inventory Imbalance and the Factors that Influence Container Inventory Management Strategies. 13th International Conference on Business Management (pp. 593-621). Sri Jayawardanepura: University of Sri Jayawardanepura.

Edirisinghe, L., Zhihong, J., \& Wijeratne, A. (2016 b). Container Inventory Management: Factors influencing Container Interchange. 13th International Conference on Business Management (pp. 652-668). Sri Jayawardanepura: University of Sri Jayawardanepura.

Edirisinghe, L., Zhihong, J., \& Wijeratne, A. (2018). Container Interchange: the 6 R Model Approach. GOL University of LeHavre. Le Havre.

Karmelic, J., Dundovic, Č., \& Kolanovic, I. (2012). Empty Container Logistics. Transport Logistics Review Traffic\&Transportation, 24(3), 223-230.

Mishra, B. (2017). M\&A to Dominate Container Shipping Sector Through 2018. Retrieved 08 11, 2018, from http://seanews.co.uk/ma-to-dominate-container-shipping-sector-through-2018/

Mittal, N. (2008). Regional Empty Marine Container Management. New Jersey: Neha Mittal.

SLPA. (2012). Performance Review. Colombo: Ceylon Association of Shipping Agents.

SLPA. (2013). Port Performance Review. Colombo: Ceylon Association of Shipping Agents.

SLPA. (2015). Port Performance Review Circular No 9/2016 of 21.01.2016. Colombo: Caylon Association of Shipping Agents. 
UNCTAD. (2017). Review of Maritime Transport. New York and Geneva: UNITED NATIONS CONFERENCE ON TRADE AND DEVELOPMENT. Retrieved May 13, 2013, from http://unctad.org/en/Docs/rmt2011ch6_en.pdf

Will, W. (2017, 04 03). www.lloydsloadinglist.com. Retrieved from www.lloydsloadinglist.com: https://www.lloydsloadinglist.com/freight-directory/news/Container-lines-make-losses-of-3.5bn-in2016/68969.htm\#.W5whCOgzbIU

Share - copy and redistribute the material in any medium or format Adapt - remix, transform, and build upon the material for any purpose, even commercially.

The licensor cannot revoke these freedoms as long as you follow the license terms.

Under the following terms:

Attribution - You must give appropriate credit, provide a link to the license, and indicate if changes were made.

You may do so in any reasonable manner, but not in any way that suggests the licensor endorses you or your use.

No additional restrictions

You may not apply legal terms or technological measures that legally restrict others from doing anything the license permits.

Journal of Sustainable Development of Transport and Logistics (ISSN: 2520-2979) is published by Scientific Publishing House "CSR", Poland, EU and Scientific Publishing House "SciView", Poland, EU

Publishing with JSDTL ensures:

- Immediate, universal access to your article on publication

- High visibility and discoverability via the JSDTL website

- Rapid publication

- Guaranteed legacy preservation of your article

- Discounts and waivers for authors in developing regions

Submit your manuscript to a JSDTL at https://jsdtl.sciview.net/ or submit.jsdt|@sciview.net 